\title{
The European Muscle Conference 2019 Special Issue
}

\author{
Elisabeth Ehler ${ }^{1} \cdot$ Steven B. Marston ${ }^{2}$
}

Published online: 2 July 2019

(c) Springer Nature Switzerland AG 2019

For its 48th annual meeting the European Society for Muscle Research (ESMR) has returned to the United Kingdom for the fifth time (Leicester 1982, Oxford 1991, York 1999, Oxford 2008) and has come to Canterbury for the first time (Schaub 2009). The Journal of Muscle Research and Cell Motility was founded by Richard Tregear and Chris Ashley in Oxford in 1980 and has been associated with ESMR for most of its life, with the first meeting abstracts being published in the Journal in its very first issue (Various 1980). It has become a tradition to also publish a special issue of the Journal together with the abstracts a few months after each meeting, but this year we are trying something novel: both the abstracts and the special issue are being published and presented at the meeting itself. We are very grateful to the efforts of Springer for the speedy processing of the manuscripts, to our referees, who kept to our tight deadlines and most of all to the authors who have produced a set of really interesting articles to a tight schedule: no-one missed the final deadline!

For this Special Issue of the Journal of Muscle Research and Cell Motility we have commissioned a series of reviews from United Kingdom (UK)-based researchers. Just looking at the surnames of the contributors it is evident just how European-wide researchers in the UK are. Muscle research involves numerous collaborations across Europe and beyond. European colleagues from all career stages working here in the UK, visits to European research institutes and facilities and last, but by no means least, generous financial support

Elisabeth Ehler

elisabeth.ehler@kcl.ac.uk

1 Randall Centre for Cell and Molecular Biophysics (School of Basic and Medical Biosciences) and School of Cardiovascular Medicine and Sciences, British Heart Foundation Research Excellence Centre, King's College London, Guy's Campus, London SE1 1UL, UK

2 National Heart and Lung Institute, Imperial College London, Cardiovascular Division, Imperial Centre for Translational and Experimental Medicine, Hammersmith Campus, Du Cane Road, London W12 0NN, UK from EU programmes mean that UK science is not an island, but integrated into a tight web with Europe and beyond. This is especially also true for conference series like the European Muscle Conference (EMC). Countless collaborations and friendships were fostered over the years by this event.

As we write this editorial, in the Ides of June 2019, the fate of the UK, as far as its political association with Europe is concerned, is still unclear. The irony that this year's EMC at Canterbury will happen in what may be year 1 of Brexit is not lost on us. For us as scientists, a severing of our connections with Europe is unthinkable. A particular feature of the EMC was always its openness and inclusiveness, especially as far as countries that were once beyond the Iron Curtain were concerned and we scientists in the UK just hope that the potential introduction of a similar political separation will not interfere with our interactions with our friends and collaborators in Europe.

London, mid June 2019.

\section{References}

Schaub MC (2009) Footsteps of the European society for muscle research (1971-2008). J Muscle Res Cell Motil 29:151-154

Various (1980) Abstracts of the eighth European conference on muscle and motility. J Muscle Res Cell Motil 1:193-245

Publisher's Note Springer Nature remains neutral with regard to jurisdictional claims in published maps and institutional affiliations. 